\title{
Resovist-Enhanced MRI for Preoperative Assessment of Colorectal Hepatic Metastases
}

\author{
A Case of Multiple Bile Duct Hamartomas Associated with Colon Cancer
}

\section{Hiroshi Suzuki $^{a} \quad$ Giichiro Tsurita $^{a}$ Soichiro Ishihara ${ }^{a}$ \\ Masaaki Akahane $^{\mathrm{b}}$ Joji Kitayama ${ }^{\mathrm{a}}$ Hirokazu Nagawa $^{\mathrm{a}}$}

Departments of a Surgical Oncology and ' ${ }^{b}$ Radiology, Graduate School of Medicine, University of Tokyo, Tokyo, Japan

\section{Key Words}

Superparamagnetic iron oxide $\cdot$ Resovist $\cdot$ Magnetic resonance imaging $\cdot$ Kupffer cell imaging $\cdot$ Colon cancer $\cdot$ Liver metastases $\cdot$ von Meyenburg complex

\begin{abstract}
Extensive preoperative assessment of hepatic metastases is required in colon cancer patients. We report a case in whom the preoperative investigation by ultrasound scan and contrast-enhanced computed tomography revealed numerous cystic lesions of the liver, suspicious of von Meyenburg complex. Magnetic resonance and magnetic resonance cholangiographic images demonstrated typical features of von Meyenburg complex. Further Resovist-enhanced magnetic resonance imaging detected two hemangiomas in addition to the multiple cystic lesions. So-called Kupffer cell imaging strongly helped the detection of these hemangiomas, and a combination of various magnetic resonance pulse sequences was of great value for the differential diagnosis of cystic lesions and hemangiomas. In cases in whom conventional imaging studies fail to give a definite diagnosis, such as in the present case, superparamagnetic iron oxide-enhanced magnetic resonance imaging is meaningful for adequate preoperative staging.
\end{abstract}

\section{Introduction}

Preoperative staging is crucial for the management of cancer patients. In colon cancer patients, extensive preoperative assessment of metastatic disease, especially liver metastases, plays a key role in the adequate clinical decision of surgical treatment. A wide range of imaging modalities, including ultrasound scan (US), computed tomography (CT), CT during arterial portography (CTAP) and magnetic resonance imaging (MRI), 
are available for the detection of hepatic metastases. In terms of the ability to detect metastases in otherwise normal liver, high diagnostic ability can be expected in each of the above techniques. However, when multiple focal lesions such as cysts, biliary hamartomas and hemangiomas exist as the background noise, the conventional screening strategy, which includes US, CT or non-enhanced MRI, will not be sufficient for the accurate detection of metastatic lesions in most of the cases.

Superparamagnetic iron oxide (SPIO), such as ferumoxides and ferucarbotrans $\left(\right.$ Resovist $^{\circledR}$ ), has recently been developed as a liver-specific MRI contrast agent to improve the detectability of hepatic tumors $[1,2]$. SPIOs contain iron particles which are phagocytosed by Kupffer cells and the reticuloendothelial system in normal liver and in most benign lesions. Since Kupffer cells are not present in metastatic lesions, administration of the contrast agent will result in improvement of the mean lesion to liver contrast ratio, resulting in an increased lesion conspicuousness on MRI. Thus, SPIO-enhanced MRI provides excellent visualization of liver metastatic lesions in the preoperative assessment of colorectal cancer patients [3].

We describe a patient with sigmoid colon cancer in whom preoperative assessment by US and contrast-enhanced CT showed numerous cystic lesions of the liver, suspicious of von Meyenburg complex, making difficult the visualization of other lesions. Resovist-enhanced MR imaging greatly helped the preoperative assessment.

\section{Case Report}

A 56-year-old man was referred to our institution with advanced carcinoma of the sigmoid colon. Preoperative assessment of metastatic disease was performed by contrast-enhanced CT scan of the thorax and the abdomen. Contrast-enhanced CT demonstrated multiple, non-enhancing, irregularly defined hypodense structures $(<1.5 \mathrm{~cm})$ in both lobes of the liver (fig. 1a). Abdominal US also revealed many hypoechoic and hyperechoic lesions scattered in both hepatic lobes (fig. 1b). Although the CT and US findings were highly suspicious of multiple bile duct hamartoma, also known as von Meyenburg complex, to exclude disseminated liver metastases, MR examination was performed. MRI confirmed the presence of multiple hypointense and hyperintense hepatic nodules, on T1-weighted gradient echo images and T2-weighted fast spin echo images, respectively (fig. 2a, b). On heavily T2-weighted images, the signal intensity increased (fig. 2c). Resovist-enhanced T1-weighted image showed no enhancement of these lesions (fig. 3c). These findings are characteristic MR features of von Meyenburg complex [46]. Further Resovist-enhanced images revealed two different lesions in hepatic segment VII and V, in addition to the numerous cystic lesions suspicious of von Meyenburg complex. Fast spoiled gradient echo sequence with a long TE and a large flip angle (so-called Kupffer cell images) detected two enhanced lesions except for cystic lesions with isointensity on this sequence (fig. 3b). These two lesions showed nodular peripheral enhancement similar to aortic attenuation on contrast-enhanced CT (fig. 3a). These hemangiomas and the multiple cystic lesions were both hypointense on T1- and hyperintense on T2-weighted images. Therefore, detection and characterization of such lesions by unenhanced MRI is a difficult matter. After injection of Resovist, these two types of lesions revealed isoand hypointensity, respectively, on T1-weighted images (fig. 3c) and iso- and hyperintensity, respectively, on T2-weighted images (fig. 3d). These findings, although not characteristic, helped to give the final diagnosis of hemangiomas. Resovist-enhanced MR findings and other imaging modalities provided no obvious evidence of metastatic lesions.

The patient received sigmoidectomy. The liver showed many tiny cystic lesions on its surface, and intraoperative US confirmed the presence of two hemangiomas, but no metastases. The postoperative course was uneventful, and the follow-up CT 18 months later showed neither change in the findings of hepatic lesions nor recurrence. Follow-up with imaging modalities including SPIO-enhanced MRI is scheduled. 


\begin{tabular}{r|l|l|l} 
Case Reports $h$ Case Rep Gastroenterol 2008;2:509-516 & Published online: December 10, 2008 & $\begin{array}{l}\text { O 2008 S. Karger AG, Basel } \\
\text { ISSN 1662-0631 } \\
\text { www.karger.com/crg }\end{array}$ \\
& & & \\
\hline
\end{tabular}

\section{Discussion}

Resectable liver metastases are found in $3 \%$ of patients with colorectal cancer [7]. If a curative resection is performed, a 5 -year survival rate of $25-30 \%$ has been shown in a large number of studies [8]. Therefore extensive preoperative investigation for liver metastases is required for the decision of the adequate treatment strategy. Previous studies have proved that SPIO definitely improves the detectability of hepatic metastases on unenhanced MR images up to the level of CTAP [3]. In our institution, US and contrast-enhanced CT are the first choice for screening of liver metastases, and SPIO-enchanced MRI and intraoperative US are performed additionally when necessary.

In the present case, the liver was diffusely occupied by cystic lesions, which led to the suspicion of von Meyenburg complex. Von Meyenburg complex, also known as multiple bile duct hamartomas or biliary hamartomas, is a benign malformation of the bile ducts in which the embryonal bile duct network has failed to involute. The US appearance of von Meyenburg complex varies between hypoechoic and hyperechoic lesions [5, 6], and some cases of von Meyenburg complex have been noted to show homogenous enhancement on contranst-enhanced CT [5,9]. Therefore, it is quite difficult to exclude other hepatic lesions, such as tumor metastasis, by US and CT. On MRI, the signal intensity on T2-weighted image progressively decreases from cysts and biliary hamartomas to hemangiomas and metastases, but the signal intensity, in most cases, overlaps, resulting in an inconclusive study [10]. Further investigation is required on how to improve the detection ability of metastatic lesions behind the background noise of numerous cysts in oncologic patients, such as in the present case.

The most effective MR pulse sequence for the detection of metastatic lesions is not a fast spin echo T2-weighted sequence, but a gradient echo sequence with a long TE, so-called $\mathrm{T} 2{ }^{*}$-weighted sequence [11]. On T2*-weighted images, both cysts and metastases show hyperintensity compared to the normal hepatic parenchyma. If $\mathrm{T} 2{ }^{*}$-weighted sequence is modified with a larger flip angle, cysts and biliary hamartomas become isointense compared to liver parenchyma, whereas metastases and hemangiomas remain hyperintense because of relatively short $\mathrm{T} 1$. This modified sequence, which is called 'Kupffer (cell) imaging', may be more suitable than the original T2* -weighted sequence for the detection of lesions hidden among cysts [12]. Indeed, Kupffer cell imaging was valuable to extract two hemangiomas from multiple cystic lesions in this patient.

However, when evaluating metastatic tumors, it is sometimes difficult to differentiate solid metastatic tumors from hemangiomas because both lesions shows high intensity on Kupffer cell images. Recently, in addition to the lesion sensitivity, the lesion specificity can also be improved by combination of various MR pulse sequences, including T2-weighted sequence and post-contrast T1-weighted sequence with Kupffer cell imaging [13-15]. Hemangiomas show high intensity on pre-contrast T2-weighted image, and a significant signal drop is observed on post-contrast T2-weighted images. On post-contrast T1-weighted image, hemangiomas show iso- or hyperintensity. On the other hand, the intensity of metastases on pre-contrast T2-weighted images is usually lower than that of hemangiomas, and the signal intensity does not change on post-contrast T2-weighted image [13, 14]. Metastases show hypointensity with the well-known 'ring enhancement' on post-contrast T1-weighted image [15]. In our patient, two different lesions were diagnosed as hemangiomas with high intensity on pre-contrast T2-weighted image and a characteristic signal drop on post-contrast T2-weighted image. 
In this case, the biliary duct hamartomas were not histopathologically proven and the hemangioma was neither radiologically nor pathologically proven and the metastases were not excluded on solid base of biopsy, but the follow-up period was 18 months. During this follow-up period, the patient had no recurrence, and we are confident that these lesions are not metastatic lesions. Moreover, in Japan, it is not ethically feasible to perform biopsy of lesions suspected of hamartomas or hemangioma, and consequently the pathological diagnosis of such lesions is unfeasible.

In conclusion, Resovist-enhanced MR imaging was useful for the detection and characterization of hepatic lesions and preoperative staging of colorectal cancer. In cases where multiple focal lesions, such as cysts and biliary hamartomas, exist as the background noise, SPIO-enhanced MRI including Kupffer cell imaging may improve the sensitivity and specificity of detection, especially of metastasic lesions. In cases in whom the conventional imaging studies fail to give a diagnosis, Resovist-enhanced MR imaging with various sets of pulse sequence is recommended for the differential diagnosis of benign and malignant hepatic lesions. 


\begin{tabular}{r|l|l|l} 
Case Reports $/$ h & $\begin{array}{l}\text { Case Rep Gastroenterol 2008;2:509-516 } \\
\text { D01: 10.1159/000183536 }\end{array}$ & Published online: December 10, 2008 & $\begin{array}{l}\text { O 2008 S. Karger AG, Basel } \\
\text { ISSN 1662-0631 } \\
\text { www.karger.com/crg }\end{array}$ \\
\hline
\end{tabular}

Fig. 1. A 56-year-old man with colon cancer and multiple cystic lesions suspicious of von Meyenburg complex. a Contrast-enhanced CT shows multiple small cystic lesions in both hepatic lobes. No enhancement is seen. b Hepatic US shows many hypoechoic and hyperechoic lesions scattered throughout the liver.
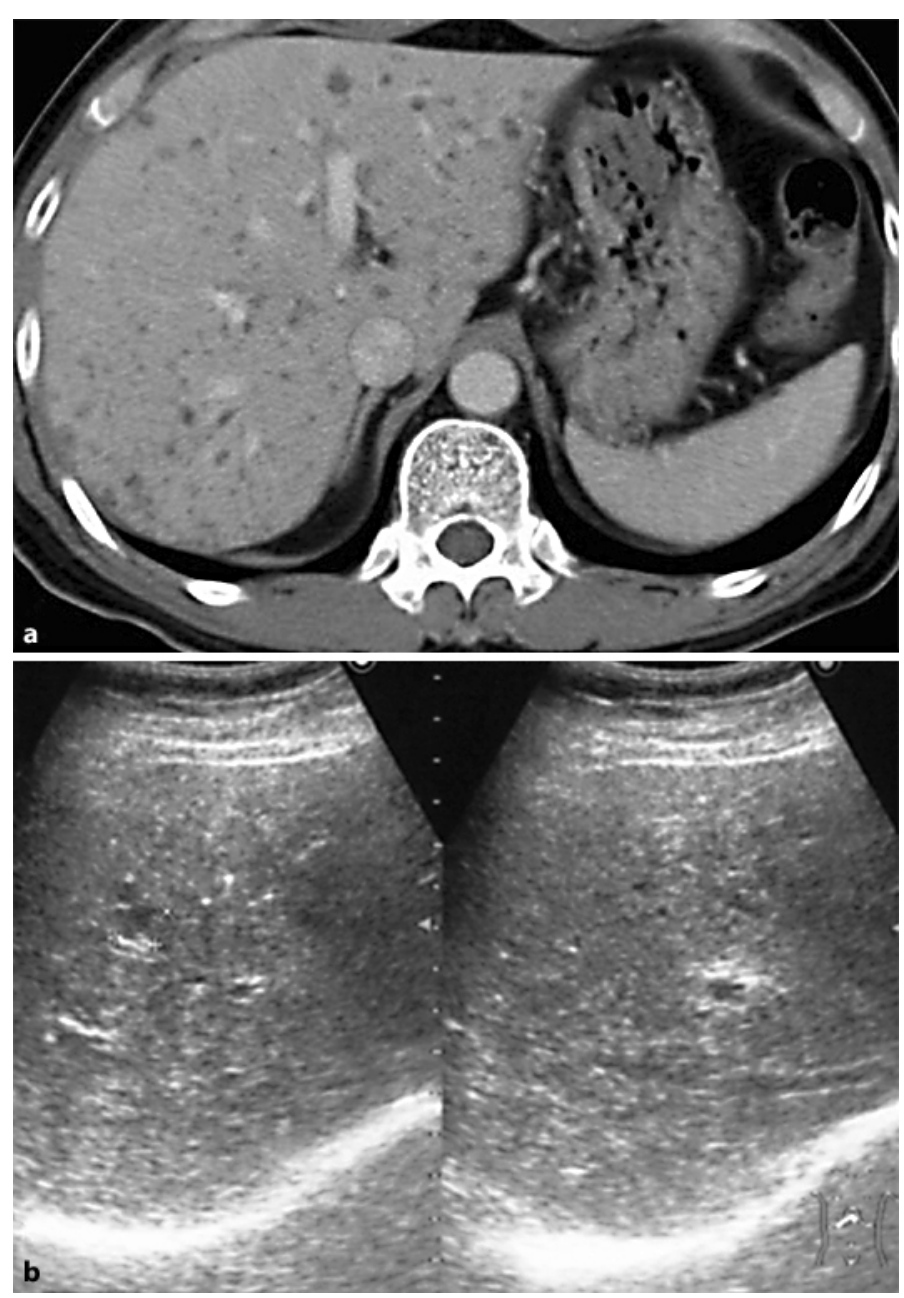


\begin{tabular}{r|l|l|l} 
Case Reports $h$ & $\begin{array}{l}\text { Case Rep Gastroenterol 2008;2:509-516 } \\
\text { Dol: 10.1159/000183536 }\end{array}$ & Published online: December 10, 2008 & $\begin{array}{l}\text { O 2008 S. Karger AG, Basel } \\
\text { ISSN 1662-0631 } \\
\text { www.karger.com/crg }\end{array}$ \\
\hline
\end{tabular}

Fig. 2. MR findings. a T1-weighted gradient echo image shows multiple hypointense liver lesions. b T2-weighted fast spin echo image shows multiple hyperintense hepatic nodules. c Heavily T2-weighted image shows that the signal intensity of the lesions further increased.
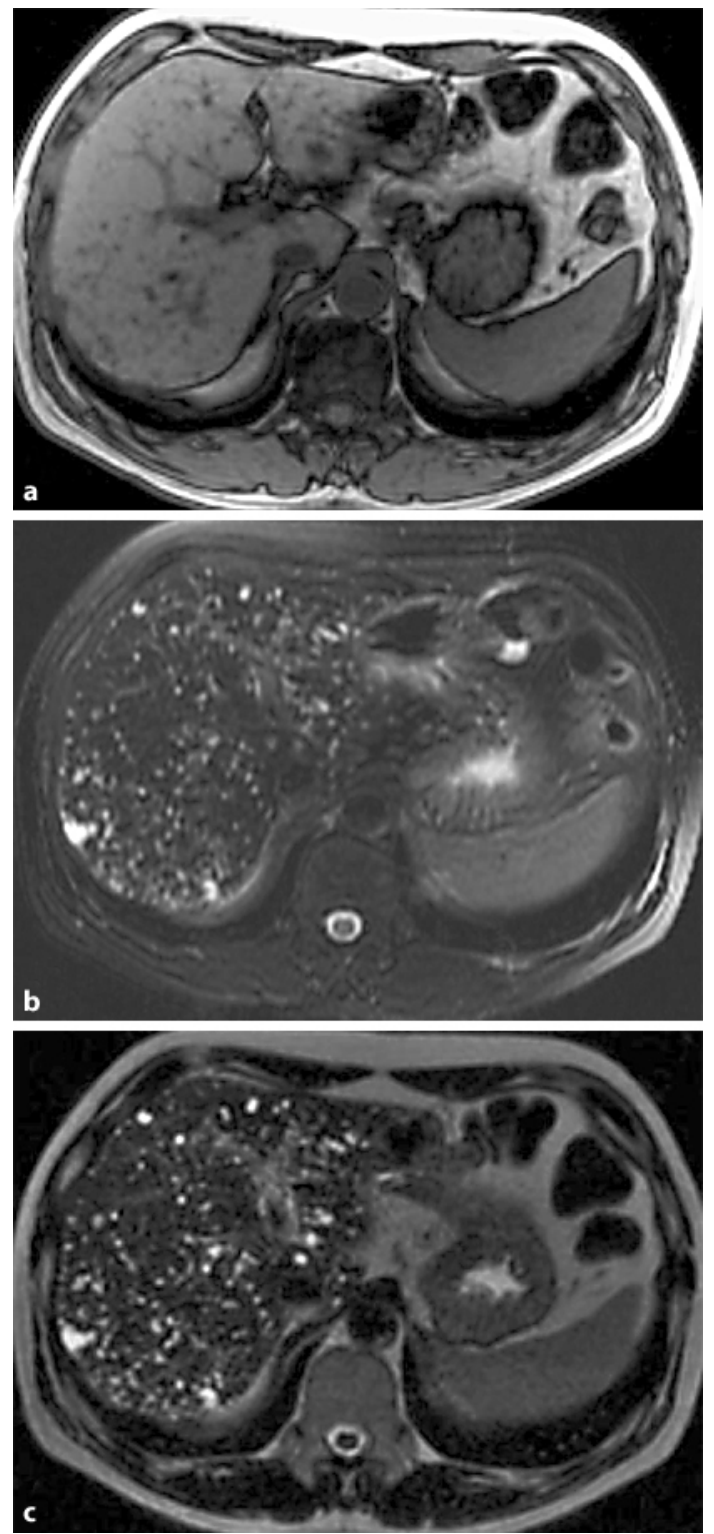
Fig. 3. Coexistence of multiple cystic lesions (arrow) and a hamangioma in hepatic segment VII (arrowhead). a Contrast-enhanced CT. b Resovist-enhanced fast spoiled gradient echo sequence with a long TE and a large flip angle (i.e. Kupffer cell image) (TR/TE/FA: 150/8.8/60 ). c SPIO-enhanced T1-weighted MR image. d SPIO-enhanced T2-weighted MR image. A hemangioma in hepatic segment VII is visible as a globular hyperdense lesion on contrast-enhanced CT image (a). On Kupffer cell image (b), this lesion becomes easily detectable because diffuse cystic lesions become isointense to liver parenchyma. The hemangioma shows almost isointense to hepatic parenchyma on T1-weighted image (c) and is seen isointense to kidney on post-contrast (d) T2-weighted images, respectively.

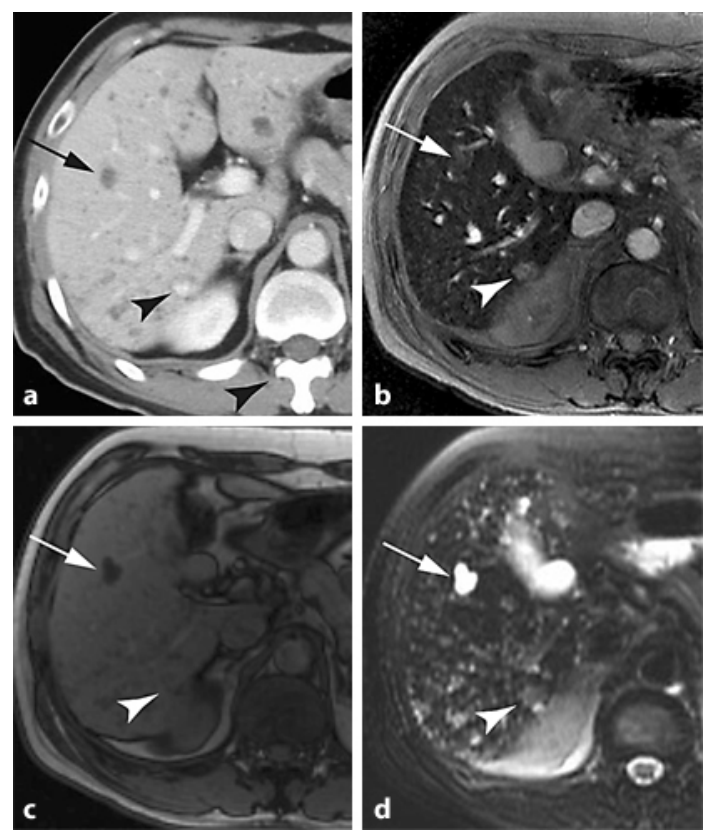




\section{References}

-1 Weissleder R, Hahn PF, Stark DD, Elizondo G, Saini S, Todd LE, Wittenberg J, Ferrucci JT: Superparamagnetic iron oxide: enhanced detection of focal splenic tumors with MR imaging. Radiology 1988;169:399-403.

-2 Fretz CJ, Stark DD, Metz CE, Elizondo G, Weissleder R, Shen JH, Wittenberg J, Simeone J, Ferrucci JT: Detection of hepatic metastases: comparison of contrast-enhanced CT, unenhanced MR imaging, and iron oxide-enhanced MR imaging. AJR Am J Roentgenol 1990;155:763-770.

-3 van Etten B, van der Sijp J, Kruyt R, Oudkerk M, van der Holt B, Wiggers T: Ferumoxide-enhanced magnetic resonance imaging techniques in pre-operative assessment for colorectal liver metastases. Eur J Surg Oncol 2002;28:645-651.

4 Slone HW, Bennett WF, Bova JG: MR findings of multiple biliary hamartomas. AJR Am J Roentgenol 1993;161:581-583.

5 Martinoli C, Cittadini G Jr, Rollandi GA, Conzi R: Case report: imaging of bile duct hamartomas. Clin Radiol 1992;45:203-205.

6 Wohlgemuth WA, Bottger J, Bohndorf K: MRI, CT, US and ERCP in the evaluation of bile duct hamartomas (von Meyenburg complex): a case report. Eur Radiol 1998;8:1623-1626.

7 August DA, Ottow RT, Sugarbaker PH: Clinical perspective of human colorectal cancer metastasis. Cancer Metastasis Rev 1984;3:303-324.

8 Nordlinger B, Guiguet M, Vaillant JC, Balladur P, Boudjema K, Bachellier P, Jaeck $D$ : Surgical resection of colorectal carcinoma metastases to the liver. A prognostic scoring system to improve case selection, based on 1568 patients. Association Française de Chirurgie. Cancer 1996;77:1254-1262.

-9 Wei SC, Huang GT, Chen CH, Sheu JC, Tsang YM, Hsu HC, Chen DS: Bile duct hamartomas. A report of two cases. J Clin Gastroenterol 1997;25:608-611.

$\checkmark 10$ Kim JH, Kim MJ, Suh SH, Chung JJ, Yoo HS, Lee JT: Characterization of focal hepatic lesions with ferumoxides-enhanced MR imaging: utility of T1-weighted spoiled gradient recalled echo images using different echo times. J Magn Reson Imaging 2002;15:573-583.

11 Arbab AS, Ichikawa T, Araki T, Toyama K, Nambu A, Ohsawa S, Kumagai H, Aikawa Y: Detection of hepatocellular carcinoma and its metastases with various pulse sequences using superparamagnetic iron oxide (SHU-555-A). Abdom Imaging 2000;25:151-158.

-12 Tanimoto A, Yuasa Y, Shinmoto H, Jinzaki M, Imai Y, Okuda S, Kuribayashi S: Superparamagnetic iron oxide-mediated hepatic signal intensity change in patients with and without cirrhosis: pulse sequence effects and Kupffer cell function. Radiology 2002;222:661-666.

13 Arbab AS, Ichikawa T, Sou H, Araki T, Nakajima H, Ishigame K, Yoshikawa T, Kumagai H: Ferumoxides-enhanced double-echo T2-weighted MR imaging in differentiating metastases from nonsolid benign lesions of the liver. Radiology 2002;225:151-158.

14 Reimer P, Jähnke N, Fiebich M, Schima W, Deckers F, Marx C, Holzknecht N, Saini S: Hepatic lesion detection and characterization: value of nonenhanced MR imaging, superparamagnetic iron oxide-enhanced MR imaging, and spiral CT-ROC analysis. Radiology 2000;217:152-158.

15 Kumano S, Murakami T, Kim T, Hori M, Okada A, Sugiura T, Noguchi Y, Kawata S, Tomoda K, Nakamura H: Using superparamagnetic iron oxide-enhanced MRI to differentiate metastatic hepatic tumors and nonsolid benign lesions. AJR Am J Roentgenol 2003;181:1335-1339. 